\title{
Study of Nutrient Utilization from Wastewater by Algae
}

\author{
Tanmayee Jahagirdar ${ }^{1}$, Sudevi Basu ${ }^{2}$ \\ Department of Biotechnology, Sir M Visvesvaraya Institute of Technology, Bengaluru-562157, Karnataka, India
}

\begin{abstract}
Nutrient pollution of wastewater and its treatment is currently one of the biggest challenges being faced in waste management in India. As nutrient pollution leads to eutrophication and algal bloom, the present research aims to reduce the nutrient load in wastewater using microalgae, before its release in water bodies. Microalgae was successfully isolated from municipal wastewater fed urban lake in Bengaluru and inoculated in domestic wastewater to carry out the treatment. Growth curve analysis and biomass studies were carried out on the microalgae isolated from lakes. The dry algal biomass was found to be $1.078 \mathrm{gm} / \mathrm{L}$ and biomass productivity was $24.5 \mathrm{mg} / \mathrm{L} / \mathrm{d}$. The nutrient removal efficiencies were found to be $33.33 \%, 66.66 \%, 80 \%$, $88.88 \%$ and $88.235 \%$ for Chemical Oxygen Demand (COD), Biological Oxygen Demand (BOD), Total Suspended Solids (TSS), Nitrate Nitrogen and Total Phosphates respectively. Crude lipid extracted was $22.54 \%$ of the weight of dry algae.
\end{abstract}

Keywords: Eutrophication, Microalgae, Nutrient pollution, COD, BOD, TSS

\section{Introduction}

Nutrient pollution is one of the rising problems in the world. Though considerable measures have been taken regarding nutrient pollution in the USA, there is a very low awareness regarding its effects in India.

Main cause for nutrient pollution is the domestic wastewater, also known as sanitary sewage, which is generated from houses and apartments. It is the primary source of pathogens and putrescible organic substances; and is a direct threat to public health. The putrescible organic substances in the wastewater decay and decompose, leading to dissolved oxygen depletion affecting the quality of lakes and streams. This in turn affects the aquatic life adversely.

Wastewater effluent, if untreated leads to various adverse effects which can be seen on the human health, environment and in turn the economy of the nation. It also depends on the quality of the effluent being released in the environment. Eutrophication is one of the many effects seen in the untreated or partially treated wastewater receiving water bodies (EPA, 2000; WHO, 2006).

Wastewater treatment involves the removal of impurities before they reach natural bodies of water such as rivers, lakes, estuaries and oceans. If the wastewater is discharged in the water bodies without following proper treatment methods, it can give rise to a lot of environmental and health problems. Wastewater treatment reduces the pollutant load and the amount of contaminants in the wastewater (Rawat et al., 2010). Primary treatment of wastewater involves the removal of solids, oil and grease from the wastewater. In the secondary treatment of wastewater, biological methods are used to remove the chemical loads present in the wastewater. Finally, the tertiary treatment involves the removal of the microbes from the effluent. The wastewater is then sent for discharge in the receiving water bodies (Rawat et al., 2010).

The effluents from the secondary treatment are high in nitrogen and phosphorus which causes eutrophication and ultimately algal bloom. Because of this reason, the treatment of the wastewater and its proper disposal is one of the major concerns and challenges being faced in the urban areas. The techniques used during the wastewater treatment usually results in a partial treatment of wastewater or it is sometimes released in the receiving water body completely untreated (Mahapatra et al., 2014).

Various conventional wastewater treatment methods have been applied to clean up the polluted water bodies. These include sedimentation, filtration, adsorption as also various biological methods like activated sludge treatment, trickling filtration, oxidation ponds, aerobic or anaerobic digestors. A lot of these techniques are applied for the nutrient removal process as well. The disadvantage of using conventional treatment methods for nutrient removal is that they require a high cost, highly energy intensive (Mahapatra et al., 2014) and lead to an increased sludge production (Yuan et al., 2011). In the past, a very special attention has been given on the removal of nitrogen and phosphates using conventional methods (Blackall et al., 2002; Mallick et al., 2002). After treatment of the wastewater also, the secondary effluent still contains a high level of nitrogen and phosphorus, thus creating a need to look for alternative treatment for nutrient pollution (Boonchai et al., 2012).

The present study is aimed at reducing the nutrient load in domestic wastewater using microalgae. There are a lot of advantages to using this method. The wastewater treatment using algae is a very eco-friendly and cost effective process (Mulbry et al., 2008). Microalgae assimilate a large amount of the nitrogen and phosphorus present in wastewater. Also, under optimal conditions, almost all available ammonia nitrogen appears in form of algal cell material. The algal biomass accumulated has the potential to be used as an energy source, feed to animals and as fertilizer in agriculture (Vilchez et al., 1997; Mulbry et al., 2006). In addition, microalgae are rich in lipids, starch and protein and this can be used as non food based feedstock for biofuels. (Chen et al., 2012). It also leads to no additional pollution and is safer ecologically and is also a very cheap method (Clarens et al., 2010, Wijffels et al., 2010). 


\section{International Journal of Science and Research (IJSR) \\ ISSN (Online): 2319-7064 \\ Index Copernicus Value (2013): 6.14 | Impact Factor (2015): 6.391}

\section{Materials and Methods}

\subsection{Microalgae culture and photobioreactor design}

Microalgae was isolated from lake water collected from Ulsoor lake, Bengaluru. It was isolated on Algae culture broth (Sodium nitrate $\mathrm{NaNO}_{3} 1 \mathrm{gms} / \mathrm{L}$, Magnesium sulphate $\mathrm{MgSO}_{4} \quad 0.513 g m s / \mathrm{L}$, Dipotassium phosphate $\mathrm{K}_{2} \mathrm{HPO}_{4}$ $0.25 \mathrm{gms} / \mathrm{L}$, Calcium chloride $\mathrm{CaCl}_{2} \quad 0.058 \mathrm{gms} / \mathrm{L}$, Ammonium chloride $\mathrm{NH}_{4} \mathrm{Cl}$ 0.05gms/L, Ferric chloride $\mathrm{FeCl}_{3} 0.003 \mathrm{gms} / \mathrm{L}$ ). Initial $\mathrm{pH}$ was adjusted to $7 \pm 0.2$. The algal pellet obtained after centrifugation at $5000 \mathrm{rpm}, 15$ minutes at $8^{0} \mathrm{C}$ was suspended in $0.85 \%$ saline. This was inoculated in wastewater and kept at room temperature with 12 hours light- 12 hours dark period. This was then used as seed culture for wastewater treatment.

Wastewater treatment was carried out in a stirred tank photo bioreactor made up of glass aquarium having 10L capacity. $6 \mathrm{~L}$ of wastewater was treated in the photo bioreactor at room temperature and constant stirring at $80 \mathrm{rpm}$ with same parameters as that of the seed culture. Wastewater treatment was carried out for a period of 45 days.

\subsection{Wastewater sampling and analysis}

Wastewater samples were obtained from „Boy“s Hostel ETP'e, SMVIT, Bengaluru; after initial grit removal and screening. This was autoclaved and then analyzed for Chemical Oxygen Demand (COD), Biological Oxygen Demand (BOD), Total Suspended Solids (TSS), Nitrate nitrogen and Total Phosphates (TP) using IS 3025. Wastewater was analyzed for above parameters at an interval of every 15 days after algae inoculation for 45 days.

\subsection{Algal growth and biomass study}

The growth of algae was determined by spectrophotometer analysis at an optical density of $670 \mathrm{~nm}$ and the reading was taken after every 48 hours. An algal growth curve was obtained using above readings. The algal species was studied using light microscope at $10 \mathrm{X}$ and $40 \mathrm{X}$ focus. The morphology of the cells was studied and the colour, shape of cells and motility was observed.

The algal biomass obtained by centrifugation after the wastewater treatment was subjected to further purification. It was filtered; air dried and kept in hot air oven at $100^{\circ} \mathrm{C}$ for 15 minutes. Dry algal biomass was measured using gravimetric method and biomass productivity was calculated using following formula:

Where,

$$
B_{\text {prod }}=\left(B_{2}-B_{1}\right) /\left(T_{2}-T_{1}\right)
$$

$B_{\text {prod }}$ : Biomass productivity $(\mathrm{g} / \mathrm{l} / \mathrm{d})$

$\left(T_{2}-T_{1}\right)$ : Time difference in the measurements of biomass concentration

$\left(B_{2}, B_{1}\right)(\mathrm{g} / \mathrm{L})$ : Concentration of biomass on $\mathrm{T}_{2}\left(45^{\text {th }}\right.$ day) and $\mathrm{T}_{1}\left(1^{\text {st }}\right.$ day)

\subsection{Lipid Extraction}

Lipid extraction was carried out using Folch method, 1959.

Dried algal biomass was homogenized in chloroform/methanol mixture (2:1) and after centrifugation, supernatant containing lipids was collected while algal biomass was discarded. After addition of water to this, supernatant was centrifuged for phase separation and lower phase of chloroform containing lipids was kept in petridish covered with plastic and tiny holes punched to allow evaporation of chloroform. After 24 hours, the crude lipid extract left behind was weighed.

\section{Results and Discussions}

\subsection{Algal culture and biomass studies}

Growth in algae isolated from lake water was observed from the $14^{\text {th }}$ day. Color of the media changed gradually and it was observed that after the initial lag phase, growth of algae was very fast. The algal seed culture in wastewater started to grow from $8^{\text {th }}$ day and the growth was higher and faster compared to that grown in Algae Culture Broth for isolation. Higher growth rate could be attributed to the high nutrient load present in wastewater as compared to the minimal media. Algal growth during wastewater treatment was observed from the $3^{\text {rd }}$ day and turbidity of wastewater reduced following complete growth of algae and there was clarity in the wastewater.

Microscopic studies (fig.1 and fig.2) show that algal cells were single celled, spherical in shape and green in color. The cells were motile, but flagella were absent. The preliminary studies based on morphological characterization suggest that algae might belong to the Chlorella species. Further studies need to be carried out to determine the strain of algae that was isolated and cultivated.

Initial spectrophotometer analysis showed lag phase to be very high. As seen from fig. 3, growth of algae gradually increased till the $23^{\text {rd }}$ day and then started declining.

The weight of the dry algal biomass was $1.078 \mathrm{gm} / \mathrm{L}$ as analyzed on the $45^{\text {th }}$ day of the wastewater treatment. This was found to be higher than the mixotrophic cultivation yield of biomass of $0.8 \mathrm{gm} / \mathrm{L}$ (Beevi et al., 2014), but was lower than the $3.1 \mathrm{gm} / \mathrm{L}$ biomass yield of Chlamydomonas polypyrenoidium on dairy wastewater as measured on the $15^{\text {th }}$ day (Kothari et al., 2013). The biomass productivity of the algae was calculated to be $24.5 \mathrm{mg} / \mathrm{L} / \mathrm{day}$. This was much lower than the earlier studies where $122.5 \mathrm{mg} / \mathrm{L} / \mathrm{d}$ was seen (Mahapatra et al., 2014) and of $57 \mathrm{mg} / \mathrm{L} / \mathrm{d}$ (Chinnasamy et al., 2010) in a raceway pond.

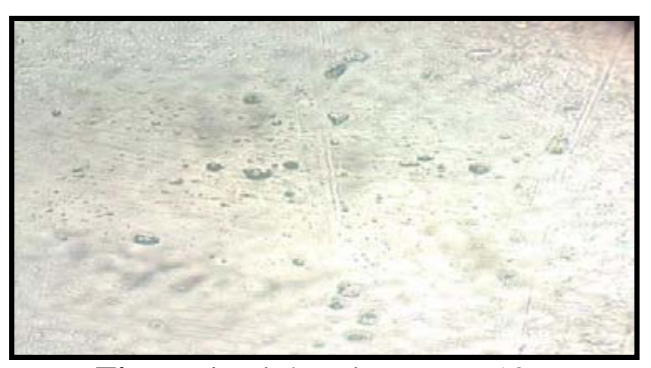

Figure 1: Light microscope 10X 


\section{International Journal of Science and Research (IJSR) \\ ISSN (Online): 2319-7064 \\ Index Copernicus Value (2013): 6.14 | Impact Factor (2015): 6.391}

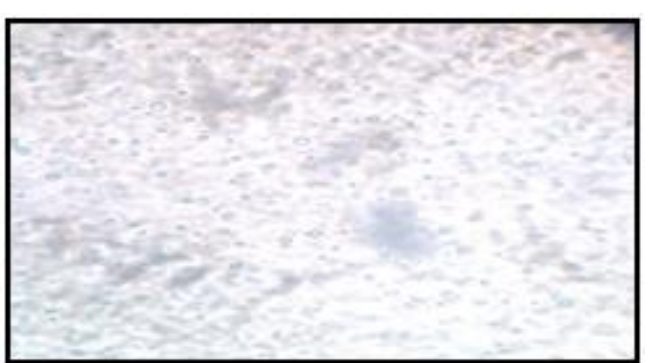

Figure 2: Light microscope 40X

\subsection{Wastewater Treatment}

Both pollutant load and nutrient load in the wastewater declined in 45 days. The values obtained every 15 days for COD, BOD, TSS, Nitrate Nitrogen and Total Phosphates are shown in fig 4, fig. 5 and fig.6. As seen in fig. 4, COD reduction was found to be $33.33 \%$ over a period of fifteen days after which no further reduction was observed in COD. This reduction is very less as compared to the previous studies, where reduction was observed to be $98 \%$ (Su et al., 2011) and 93\% (Beevi et al., 2014).

In this study, BOD reduction was $66.67 \%$ at the end of 45 days. Previous studies show a greater decrease in BOD of 82\% in fifteen days (Beevi et al., 2014) and 89.6\% using Chlorella vulgaris (Azeez., 2010). The TSS reduced gradually over a period of 45 days and from figure 4 the reduction was seen as $80 \%$.

As seen in fig. 6, in the present study, total phosphates reduction after fifteen days was $64.7 \%$ and total reduction was seen to be $88.235 \%$ after 45 days. These results are higher as compared to $70 \%$ removal (Mahapatra et al., 2014), 72\% removal (Wang et al., 2013), 70\% removal (Kothari et al., 2013) in dairy effluent. But it was a little lower than phosphate removal in piggery wastewater treatment which was more than $90 \%$ within five days. Uptake of phosphates was seen to be higher for the initial 20 days compared to that of nitrate nitrogen. Uptake of nitrogen by algae was observed to increase exponentially after the $30^{\text {th }}$ day. The percentage reduction of pollutant load was highest in Nitrate Nitrogen and Total Phosphates as compared to the other wastewater parameters. Based on this observation, it can be suggested that the treatment of wastewater using algae is a viable option for the reduction of nutrient load.

The studies involving nitrate nitrogen and total phosphates reduction in the wastewater showed significant results. As seen from fig. 5 , the nitrate nitrogen reduction was observed to be $88.88 \%$. This was higher than $67 \%$ removal from wastewater using mixed algal cultures (Prathima et al., 2012). It was almost similar to other studies conducted where reduction was 90\% (Kothari et al., 2013) in dairy effluent.

\subsection{Lipid Extraction}

The crude lipid extracted weighed $0.243 \mathrm{gm} / \mathrm{L}$. The percentage of lipid content from dry biomass was found to be $22.54 \%$. This lipid still contained impurities like algal pigments and cell suspension. Further purification would give an even lesser quantity of lipid in the algae. The above lipid content was less as compared to the other studies where lipid content has been found to be 28.5\% (Mahapatra et al., 2014). The lipid content might have been less as it was measured in the stationary phase of algae. Studies have shown

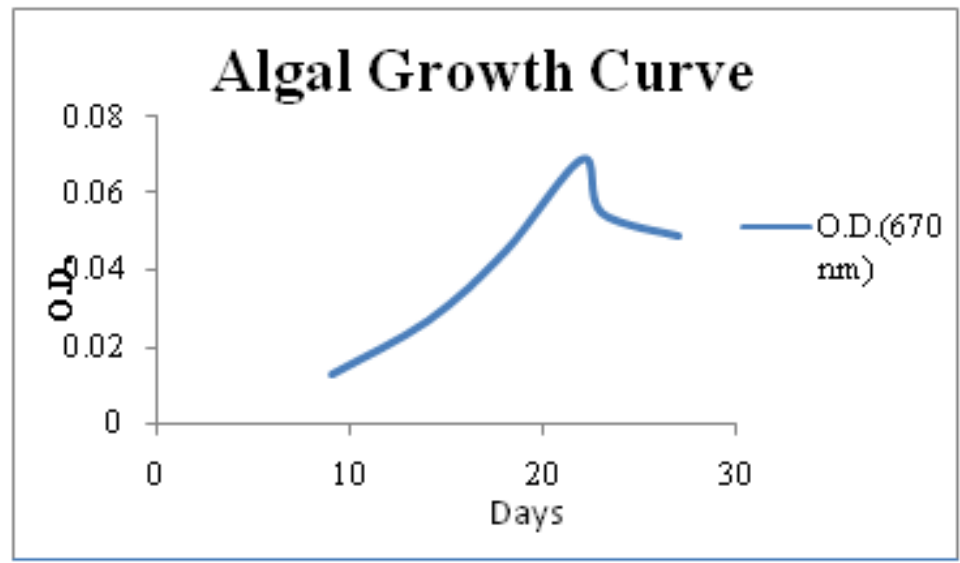

Figure 3: Spectrophotometer analysis of algal growth 


\section{International Journal of Science and Research (IJSR) \\ ISSN (Online): 2319-7064}

Index Copernicus Value (2013): 6.14 | Impact Factor (2015): 6.391

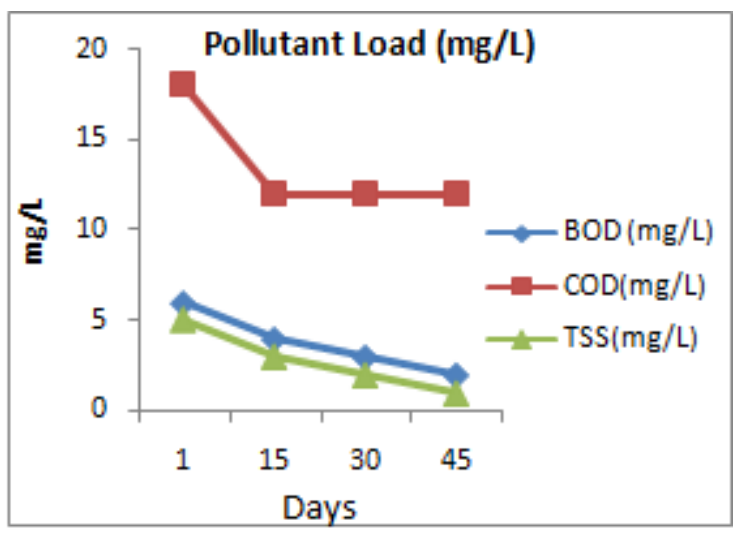

Figure 4: Reduction in pollutant load

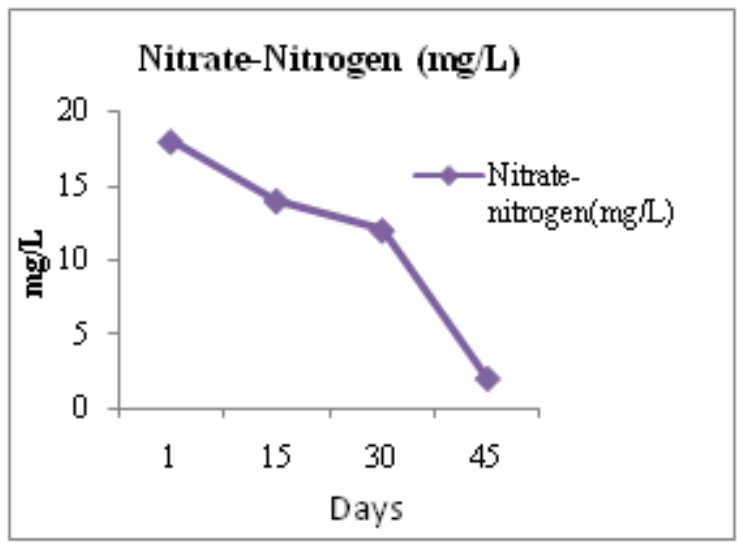

Figure 5: Reduction in Nitrate Nitrogen

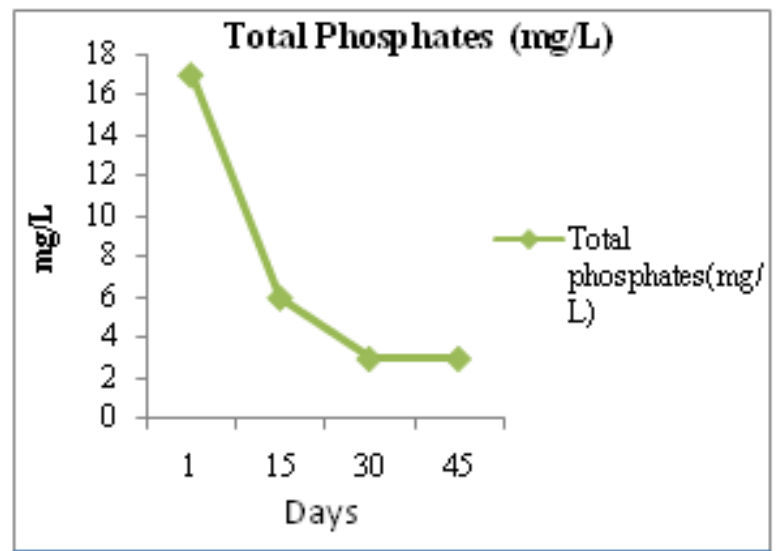

Figure 6: Reduction in Total Phosphates

that higher lipid content was observed in the cells with exponential phase and optimum biomass (Kothari et al., 2013). The crude lipid extracted still contained pigmented algae and was observed to be dark green in color.

\section{Conclusions}

Studies on nutrient removal from wastewater using microalgae were successfully carried out and it was observed that this method has given fairly good results. A photobioreactor was constructed by modifying a glass aquarium tank of capacity 10L. Growth studies for algal biomass was carried out and dry weight of algae was 1.078 $\mathrm{gms} / \mathrm{L}$ and the biomass productivity was $24.5 \mathrm{mg} / \mathrm{L} / \mathrm{d}$. Reduction in pollutant load for COD, BOD, TSS was $33.33 \%, 66.66 \%$ and $80 \%$ respectively. Reduction in the nutrient load was higher compared to the other wastewater parameters analyzed. Nitrate Nitrogen and Total Phosphates reduced by $88.88 \%$ and $88.235 \%$ respectively. Thus algae can be used to remove nutrients from domestic wastewater. Crude lipid of $22.54 \%$ from the dry algal biomass was successfully extracted and this has the potential to be used as non-food based substrate for lipid extraction.

\section{Acknowledgements}

The authors would like to sincerely thank the Karnataka State Council for Science and Technology for their financial help in the project. They would like to extend their gratitude to the Bangalore Analytical Research Center (P) Ltd for help in getting wastewater analysis done. The authors would also like to thank the Department of Biotechnology, Sir MVIT for the support during the research.

\section{References}

[1] Azeez R.A. (2010), "A study on the effect of temperature on the treatment of industrial wastewater using Chlorella vulgaris"; Algae J. Eng. Technology, Vol. 28, pp. 1-8

[2] Beevi U S, Sukumaran R K (2014), "Cultivation of microalgae in dairy effluent for oil production and removal of organic pollution load"; Bioresource Technology, Vol. 165, pp. 295-301

[3] Blackall L.L., Crocetti G R, Saunders A M, Bond P L (2002), "A review and update of the microbiology of enhanced biological phosphorus removal in wastewater treatment plants"; Antonic Leeuwenhoeck, Vol. 81, pp. 681-692

[4] Boonchai R, Seo G T, Park D R, Seong C Y (2012), "Microalgae photobioreactor for Nitrogen and Phosphorus removal from wastewater of sewage treatment plant"; International Journal of Bioscience, Biochemistry and Bioinformatics, Vol. 2, No. 6, pp. 407-410

[5] Chen R, Li R, Deitz, L, Liu Y, Stevenson R J, Liao W (2012), " Freshwater algal cultivation with animal waste for nutrient removal and biomass production"; Biomass and Bioenergy, Vol. 39, pp. 128-138

[6] Chinnasamy, S., Bhatnagar, A., Hunt, R.W., Das, K.C., (2010), "Microalgae cultivation in a wastewater dominated by carpet mill effluents for biofuel applications"; Bioresource. Technology, 101, pp. 30973105.

[7] Clarens A F, Resurrection E P, White M A, Colosi L M (2010), “ Environmental lifecycle comparison of algae to other bioenergy feedstocks"; Environmental Science Technology, Vol.44, pp. 1813-1819

[8] Kothari R, Prasad R, Kumar V, Singh D P (2013), "Production of biodiesel from microalgae Chlamydomonas polypyrenoidium grown on dairy industry wastewater"; Bioresource Technology, Vol. 144, pp. 499-503

[9] Mahapatra D.M., Chanakya H.N., Ramachandra T.V. (2014); " Bioremediation and lipid synthesis through mixotrophic algal consortia in municipal wastewater"; Bioresource Technology, Vol. 168, pp. 142-150

[10] Mallick N. (2002), "Biotechnological potential of immobilized algae for wastewater Nitrogen, Phosphorus

\section{Volume 5 Issue 4, April 2016}


and metal removal: A review"; Biometals, Vol.15, pp. 377-390

[11] Mulbry W, Kondrad S, Pizarro P(2006), "Biofertilizers from algal treatment of dairy and swine manure effluents: Characterization of algal biomass as slow release fertilizer"; Journal of Vegetable Science, Vol. 12, pp. 107-125

[12] Mulbry W, Kondrad S, Pizarro C, Kebede-Westhead E.(2008), " Treatment of dairy manure effluent using freshwater algae: Algal productivity and recovery of manure nutrients using pilot scale algal turf scrubbers"; Bioresource Technology, Vol. 99, pp. 8137-8142

[13] Prathima Devi, M., Venkata Subhash, G., Venkata Mohan, S., (2012), "Heterotrophic cultivation of mixed microalgae for lipid accumulation and wastewater treatment during sequential growth and starvation phases and effect of nutrient supplementation" J. Renew. Energy Vol. 43, pp. 276-283.

[14] Rawat I, Kumar R, Mutanda T, Bux, F (2010), “Dual role of microalgae: Phycoremediation of domestic wastewater and biomass production for sustainable biofuels production"; Applied Energy, doi:10.1016/j.apenergy.2010.11.025

[15] Su Y, Mennerich A, Urban B (2011), “Municipal wastewater treatment and biomass accumulation with a wastewater born and settlable algal-bacterial culture"; Water Research, Vol. 45, Issue 11, pp. 3351-3358

[16] Vilchez C, Garhayo I, Lobato M V, Vega J M (1997), "Microalgae mediated chemicals production and wastes removal"; Enzyme Microbiology Technology, Vol.20, pp. 562-572

[17] Wang C, Yu X, Lu H, Yang J (2013), “Nitrogen and Phosphorus removal from municipal wastewater by the green alga Chlorella sp"; Journal of Environmental Biology, Vol. 34, pp. 421-425

[18] Wijffels R H, Barbosa M J (2010), “An outlook on microalgal biofuels"; Science, Vol. 329, pp. 796-799

[19] Yuan X, Kumar A, Sahu K, Ergas S J (2011), “Impact of ammonia concentration on Spirulina platensis growth in an airlift bioreactor"; Bioresource Technology, Vol. 102, pp. 3234-3239

[20] www2.epa.gov/nutrientpollution

[21] http://www.who.int 